\title{
Heat Transfer of Non-Newtonian Dilatant Power Law Fluids in Square and Rectangular Cavities
}

\author{
I. Vinogradov, L. Khezzar ${ }^{\dagger}$ and D. Siginer \\ The Petroleum Institute, Mechanical Engineering Department \\ Po Box 2533, Abu Dhabi, United Arab Emirates \\ $\dagger$ †orresponding Author Email: lkhezzar@pi.ac.ae
}

(Received April 25, 2010; accepted March 13, 2011)

\begin{abstract}
Steady two-dimensional natural convection in fluid filled cavities is numerically investigated for the case of nonNewtonian shear thickening power law liquids. The conservation equations of mass, momentum and energy under the assumption of a Newtonian Boussinesq fluid have been solved using the finite volume method for Newtonian and non-Newtonian fluids. The computations were performed for a Rayleigh number, based on cavity height, of $10^{5}$ and a Prandtl number of 100. In all of the numerical experiments, the channel is heated from below and cooled from the top with insulated side-walls and the inclination angle is varied. The simulations have been carried out for aspect ratios of 1 and 4. Comparison between the Newtonian and the non-Newtonian cases is conducted based on the dependence of the average Nusselt number on angle of inclination. It is shown that despite significant variation in heat transfer rate both Newtonian and non-Newtonian fluids exhibit similar behavior with the transition from multi-cell flow structure to a single-cell regime.
\end{abstract}

Keywords: Cavity, Power-law fluids, Numerical, Heat transfer.

\section{NOMENCLATURE}

\begin{tabular}{|c|c|c|c|}
\hline A & Surface area $\left(\mathrm{m}^{2}\right)$ & $\mathrm{T}_{\mathrm{C}}$ & Cold wall temperature \\
\hline AR & Aspect ratio $(=\mathrm{L} / \mathrm{H})$ & $\mathrm{T}$ & Fluid temperature \\
\hline D & Rate of strain & $\mathrm{u}, \mathrm{v}$ & Flow velocity components in $\mathrm{x}$ and \\
\hline g & Gravitational acceleration $\left(\mathrm{m} / \mathrm{s}^{2}\right)$ & & y directions respectively $(\mathrm{m} / \mathrm{s})$ \\
\hline $\mathrm{H}$ & Height of cavity & \multicolumn{2}{|r|}{ Greek Symbols } \\
\hline K & Consistency index & $\beta$ & Fluid expansion coefficient $\left(\mathrm{K}^{-1}\right)$ \\
\hline $\mathrm{L}$ & Width of cavity & $\phi$ & Angle of inclination (deg) \\
\hline $\mathrm{n}$ & power-law index & $\kappa$ & Thermal diffusivity of fluid $\left(\mathrm{m}^{2} / \mathrm{s}\right)$ \\
\hline $\mathrm{Nu}$ & Nusselt number & $\mu$ & Dynamic viscosity \\
\hline $\mathrm{p}$ & Pressure $\left(\mathrm{N} / \mathrm{m}^{2}\right)$ & $\begin{array}{l}\mu \\
\nu\end{array}$ & Kinematic viscosity $\left(\mathrm{m}^{2} / \mathrm{s}\right)$ \\
\hline $\operatorname{Pr}$ & Prandtl number & & Fluid density $\left(\mathrm{kg} / \mathrm{m}^{3}\right)$ \\
\hline $\mathrm{Ra}$ & Rayleigh number based on the & & \\
\hline & height $\mathrm{H}$ of the cavity & $\psi$ & $\begin{array}{l}\text { Stress } \\
\text { Stream function }\end{array}$ \\
\hline
\end{tabular}

\section{INTRODUCTION}

Flows of Newtonian and non-Newtonian fluids driven by buoyancy in rectangular enclosures are found in a variety of engineering applications such as pulp paper, slurry transport, food processing and polymer engineering. For differentially heated two-dimensional enclosures with adiabatic side walls, the heat transfer characteristics are influenced by the inclination of the cavity with respect to the horizontal plane, Prandtl number, and the Rayleigh number based on the height of the cavity. Although the case of Newtonian liquid

has been thoroughly investigated (see Gebhart et al. (1988), Ostrach (1972) and Khalifa (2001) for a review), there is only a limited number of articles dealing with the non-Newtonian case.

It seem, that the numerical study by Ozoe and Churchill (1972) aimed at determining the threshold for the onset of Rayleigh-Bernard convection in power law fluids was one of the first in the field. The critical Rayleigh number was found to increase with the flow behavior index, but, compared to the experimental and theoretical data reported by Tien et al. (1969), showed a 
tendency to give exaggerated values. More recently, Kim et al. (2003) considered transient buoyant convection in a square cavity subjected to hot and cold temperature on the vertical side walls for Newtonian and non-Newtonian power law fluids of the Ostwald-De Waele model. The study concluded that for high Ra $10^{5}$ $10^{7}$ and Prandtl number $10^{2}-10^{4}$ as the power law index $\mathrm{n}$ decreases, the convective activity is intensified with consequent enhancement of the overall heat transfer coefficient. This means that the evolution of the flow in the transient process is made faster. Ohta et al. (2002) studied numerically transient heat transfer in a square cavity heated from the bottom and cooled from the top using the Sutherby model for shear thinning fluids, such as aqueous solutions of Natrosol $250 \mathrm{H}$ hydroxyethyl cellulose and found that shear thinning resulted in larger heat transfer rates than Newtonian fluids. Furthermore their study revealed that for highly pseudoplastic fluids and for large Rayleigh number equal to $10^{5}$ complex flow patterns consisting of unstable multi roll-cells are generated leading to an oscillating $\mathrm{Nu}$ with time. As for rectangular cavities, one can mention the studies of Inaba et al. (2003) and Lamsaadi et al. (2006).

To the authors knowledge it appears that no study is available on thermal convection of non-Newtonian shear thickening fluids in two-dimensional tilted enclosures heated from below (and cooled from above) under a constant wall temperature assumption. Thus the main objective of this article is to study the effect of shear-thickening on heat transfer rate in such a geometry using the power-law model of Ostwald-De Waele fluids and a Newtonian fluid with a high Prandtl number. The steady state numerical solution is obtained for a square and rectangular cavity with aspect ratio of 4, Rayleigh and Prandtl numbers of $10^{5}$ and 100 respectively.

\section{Mathematical AND Numerical Model}

A two dimensional rectangular cavity filled with a nonNewtonian fluid is considered. The inclination angle of the cavity varies between $0^{\circ}$ and $90^{\circ}$. The aspect ratio is $\mathrm{AR}=\mathrm{L} / \mathrm{H}$, the ratio of the length $\mathrm{L}$ of the isothermal walls to the length $\mathrm{H}$ of the adiabatic walls. The top (cold) and the bottom (hot) surfaces of the cavity are maintained at constant temperatures $T_{c}$ and $T_{h}$, while the two side walls are kept adiabatic as shown in Fig. 1.

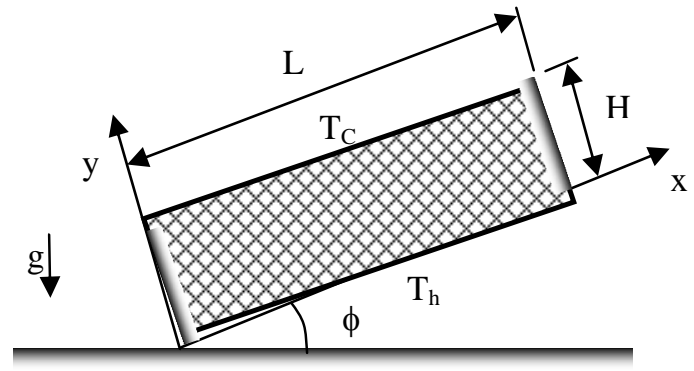

Fig. 1. Geometrical configuration

Flow in the cavity is assumed laminar, steady and twodimensional. Boussinesq approximation holds and viscous dissipation is assumed to be negligible. The buoyancy force is caused only by the density gradient, thus:

$$
\frac{\rho}{\rho_{0}}=1-\beta\left(T-T_{0}\right)
$$

where $\beta$ is the coefficient of thermal expansion, $\rho$ is the fluid density at temperature $T$ and $\rho_{0}, \mathrm{~T}_{0}$ are the corresponding reference values respectively. The field conservation equations of mass, momentum and energy are given by:

$\frac{\partial u}{\partial x}+\frac{\partial v}{\partial y}=0$

$u \frac{\partial u}{\partial x}+v \frac{\partial u}{\partial y}=-\frac{1}{\rho_{0}} \frac{\partial p}{\partial x}+\frac{1}{\rho_{0}}\left(\frac{\partial \tau_{x x}}{\partial x}+\frac{\partial \tau_{x y}}{\partial y}\right)+g \beta \Delta T \sin \phi$

$u \frac{\partial v}{\partial x}+v \frac{\partial v}{\partial y}=-\frac{1}{\rho_{0}} \frac{\partial p}{\partial y}+\frac{1}{\rho_{0}}\left(\frac{\partial \tau_{x y}}{\partial x}+\frac{\partial \tau_{y y}}{\partial y}\right)+g \beta \Delta T \cos \phi$

$u \frac{\partial T}{\partial x}+v \frac{\partial T}{\partial y}=\kappa\left(\frac{\partial^{2} T}{\partial x^{2}}+\frac{\partial^{2} T}{\partial y^{2}}\right)$

Where the velocity vector is expressed in terms of its Cartesian components $(u, v)$ along the $\mathrm{x}$ and $\mathrm{y}$ directions of the coordinate system shown in Fig. $1 ; p$, $v, \kappa$ and $g$ represent the pressure, the kinematic viscosity, the thermal diffusivity and the acceleration of gravity, respectively.

The non-Newtonian power law is considered and is given by:

$\tau_{i j}=\mu_{a} D_{i j}=K e^{T_{0}} / T\left(\frac{1}{2} D_{k l} D_{k l}\right)^{\frac{(n-1)}{2}} D_{i j}$

where the rate of strain is given by $D_{i j}=\left(\partial u_{i} / \partial x_{j}+\partial u_{j} / \partial x_{i}\right)$ and $K$ and $n$ are the consistency and the power-law index respectively. $n=1$ corresponds to Newtonian case and $n>1$ corresponds to shear-thickening. It is now necessary to introduce a physical quantity with dimensions of (length) $)^{2}(\text { time })^{-1}$ which would play a role analogous to the kinematic viscosity of a Newtonian fluid. The introduction would facilitate interpretation of results in conjunction with tools that are effective for a Newtonian fluid.

In literature, searches for the proper combinations of flow variables have been made both for free convection about a flat plate see, Khezzar \& Siginer (2009), Emery et al. (1971) and Dale and Emery (1972) and for a porous cavity Getachew et al. (1996). Based on the physical rationalization and trial-and -error efforts, the following expression similar to a kinematic viscosity of a Newtonian fluid is introduced:

$v^{\prime}=\left(\frac{K}{\rho_{0}}\right)^{\frac{1}{(2-n)}} H^{\frac{2(1-n)}{(2-n)}}$

Substituting this analog of kinematic viscosity into the traditional expressions for Prandtl and Rayleigh numbers Soong et al. (1996), the corresponding parameters for a non-Newtonian fluid can now be defined as:

$\operatorname{Pr}=\left(\frac{K}{\rho_{0}}\right)^{\frac{1}{(2-n)}} H^{\frac{2(1-n)}{(2-n)}} / \kappa$ 
and

$$
R a=\frac{g \beta \Delta T H^{3}}{\kappa\left(\frac{K}{\rho_{0}}\right)^{\frac{1}{(2-n)}} H^{\frac{2(1-n)}{(2-n)}}}
$$

The area-average Nusselt number on the conducting walls is defined as follows:

$$
N u=\frac{1}{A} \int_{0}^{A}\left(\frac{\partial T}{\partial y}\right)_{\text {wall }} d x
$$

The conservation equations are solved numerically using the finite volume technique using the Fluent code. The Simple algorithm, the Quick scheme and PRESTO technique were used for the velocity-pressure coupling, convective terms discretization, and pressure interpolation respectively. Convergence was assumed when the normalized residuals reached $5 \times 10^{-5}, 10^{-5}$ and $10^{-6}$ in monitoring for the mass residuals, momentum and energy equations respectively. All calculations were performed in double precision mode.

In addition, the results of Kim et al. (2003) for a square cavity were used to validate the calculation method and approach. This test case consisted of calculations for a square geometry at an angle of inclination of $90^{\circ}$ with $R a=10^{5}$ and three Prandtl numbers $\operatorname{Pr}=10^{2}, \operatorname{Pr}=10^{3}$ and $\operatorname{Pr}=10^{4}$. The dependence of the relative Nusselt number on power law index is presented on Fig. 2. The results are in full agreement with those of Kim et al. (2003) with an excellent accuracy of less than $1 \%$.

\section{RESULTS}

Calculations were performed for three aspect ratios 1 , and 4 and Rayleigh and Prandtl numbers of $10^{5}$, and 100. The Rayleigh and Prandtl number values are representative of practical applications see Pittman et al. (1999) and Prandtl numbers for most nonNewtonian fluids are high.

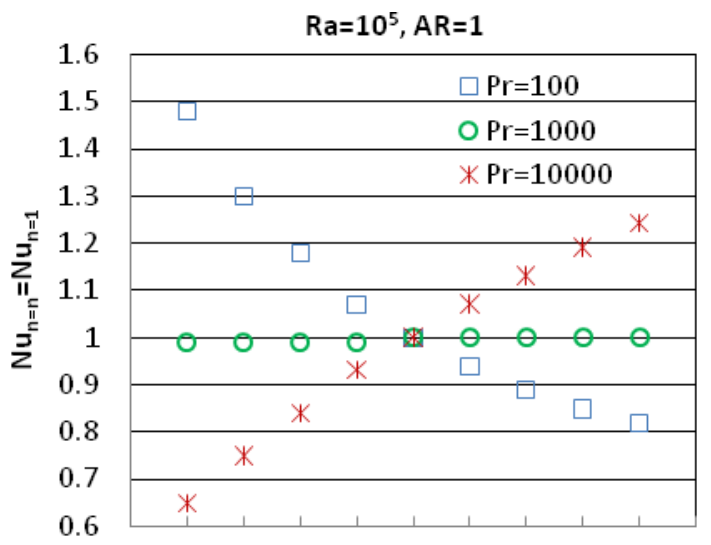

$\begin{array}{llllllllllll}0.5 & 0.6 & 0.7 & 0.8 & 0.9 & 1 & 1.1 & 1.2 & 1.3 & 1.4 & 1.5\end{array}$

Power-law index ( $\mathrm{n}$ )

Fig. 2. Variation of the relative Nusselt number for $R a=10^{5}$ and $\mathrm{AR}=1$

The power law fluids considered include shear thinning, shear thickening and Newtonian with a power index $0.6 \leq n \leq 1.4$ for the square cavity and shear thickening for the rectangular cavity.

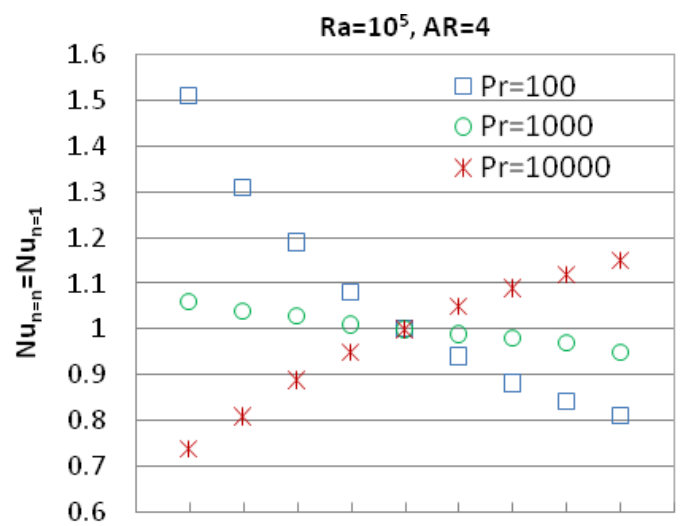

$\begin{array}{llllllllllll}0.5 & 0.6 & 0.7 & 0.8 & 0.9 & 1 & 1.1 & 1.2 & 1.3 & 1.4 & 1.5\end{array}$

Power-law index (n)

Fig. 3. Variation of the relative Nusselt number for (a) $R a=10^{5}$ and $\mathrm{AR}=4$

Figures 2-3 illustrate the variation of the Nusselt number for each exponent $\mathrm{n}$ normalized by the corresponding value for a Newtonian fluid $(n=1.0)$ when the angle of inclination is equal to $90^{\circ}$ and for each aspect ratio 1 and 4 respectively and the Rayleigh number considered. Several observations can be made, for shear thinning fluids $(\mathrm{n}<1.0)$ the overall heat transfer is augmented for $\operatorname{Pr}=10^{2}$ and $10^{3}$ with a pronounced increase as the exponent $\mathrm{n}$ decreases as found in Lamsaadi et al. (2006) but is decreased for $\mathrm{Pr}=10^{4}$. The aspect ratio also influences the augmentation in heat transfer positively, albeit in an imperceptible way. The Prandtl number effect was also observed by Kim et al. (2003) where a non-Newtonian fluid with large $\operatorname{Pr}=10^{4}$ and low $\mathrm{Ra}=10^{5}$, the $\mathrm{Nu}$ values found are less than those of a Newtonian fluid. In contrast, for shear thickening fluids $(n>1.0)$ the opposite can be observed. Shear thickening fluids inhibit heat transfer in comparison with a Newtonian fluid except for $\operatorname{Pr}=10^{4}$. It appears that there is a competing effect between momentum and heat transfer at high Pr. Thus and in comparison with the Newtonian case heat transfer is reduced for shear thinning fluids and increased for shear thickening fluids when the angle of inclination is $90^{\circ}$.

Figure 4 shows the variation of the average Nusselt number on the conducting walls with angle of inclination for aspect ratio $A R=1$. The variation of $\mathrm{Nu}$ is monotonic with shear thickening fluids exhibiting lower values of $\mathrm{Nu}$ than the Newtonian case values. An increase in $\mathrm{Ra}$ increases the $\mathrm{Nu}$ for all fluid types and the increase is more pronounced for Newtonian fluids. The location of the maximum values is found between $65-70^{\circ}$.

The variations of $\mathrm{Nu}$ with angle of inclinations for $\mathrm{AR}=4$ is shown on Fig. 5. The $\mathrm{Nu}$ varies in a non monotonic fashion showing a sudden decrease followed by a monotonic increase towards the value at $90^{\circ}$ inclination. The sudden drop in $\mathrm{Nu}$ occurs at around an angle of $45^{0}$. The Sudden drop is a result of flow mode change. Globally shear thickening tends to reduce the heat transfer in comparison with the Newtonian fluid. Figures 6 and 7 present typical flow patterns when $\mathrm{AR}=1$ and for $n=1$ (Newtonian case) and $n=1.4$ (shear- 
thickening). It can be seen that the flow consists of onecell structure throughout the inclination angle variation from 0 to $90^{\circ}$ and therefore no discontinuities exist in the Nusselt number variation. In line with previous research shear-thickening decreases the heat transfer though mush less significantly. Despite strong dependence of Nusselt number at a fixed angle on the power-law index, very little difference can be observed in the flow structure for each fluid type.

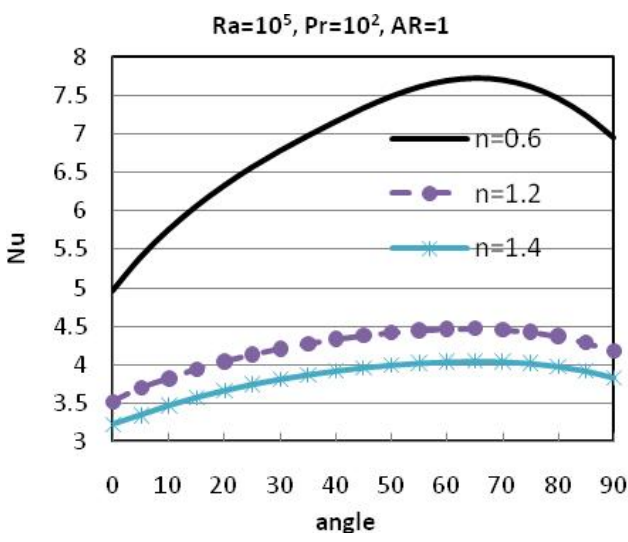

Fig. 4. Average Nusselt number for $P r=100 \mathrm{AR}=1$ : $R a=10^{5}$

Figure 7 illustrate contours of the stream function for $\mathrm{AR}=4$ case. It can be seen that in the vicinity of zero angle the flow has a multi-cell structure though the number of cells depends on the power-law index. At around $10^{\circ}-20^{\circ}$ the first transition takes place. The flow structure changes dramatically with a consequent and significant change in the Nusselt number for the Newtonian case. For non-Newtonian fluids, this change in flow structure has much less pronounced effect on the overall heat transfer rate. The second transition takes place between $40-50^{\circ}$ leading to the usual singlecell flow. The results also show the influence of Prandtl number on stability of the flow for this work.
The present Prandtl number value is 100 and transition to a one-cell structure takes place sequentially in twostages while in Corcione (2003) and Khezzar \& Siginer (2009) for a Newtonian fluid the Prandtl number is 10 and for similar Rayleigh number and aspect ratio the transition takes place in one single stage.

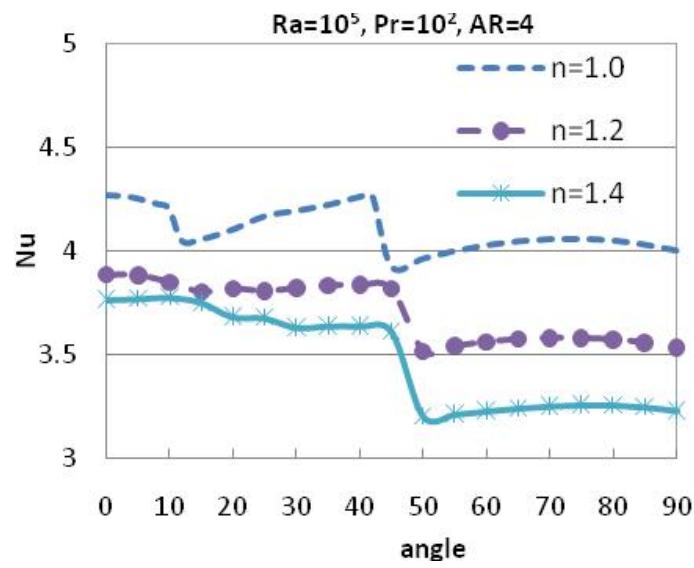

Fig. 5. Average Nusselt number for $\operatorname{Pr}=100 \mathrm{AR}=4$ :

$$
R a=10^{5}
$$

\section{Conclusions}

Natural convection of both Newtonian and nonNewtonian liquids in two dimensional rectangular tilted enclosures were investigated numerically for angles between 0 and $90^{\circ}$. Flow configuration and heat transfer behavior due to natural convection in square and rectangular enclosures of aspect ratio 4 for $\mathrm{Ra}=10^{5}$ and $P r=100$ have been examined.

The results show that shear-thickening fluids have moderately lower heat transfer rates than Newtonian fluids for the Rayleigh and Prandtl numbers considered and tend to have a stabilizing effect on the flow with a rapid transition to a single roll structure.

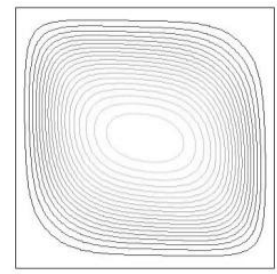

$\phi=0^{0}$

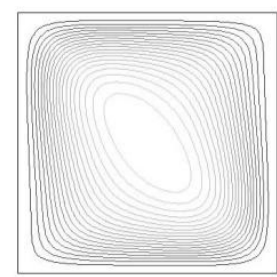

$\phi=45^{0}$

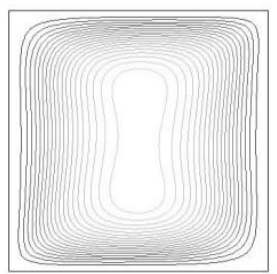

$\phi=90^{\circ}$

Fig. 6. Contours of stream function, $\operatorname{Ra}=10^{5}, \operatorname{Pr}=100$ and $\mathrm{AR}=1, n=1$

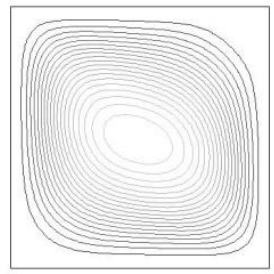

$\phi=0^{0}$

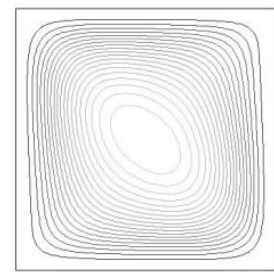

$\phi=45^{0}$

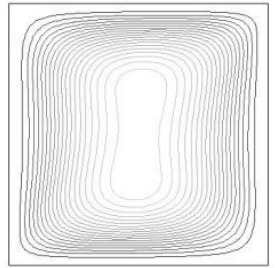

$\phi=90^{\circ}$

Fig. 7. Contours of stream function, $R a=10^{5}, \operatorname{Pr}=100$ and $\mathrm{AR}=1, n=1.4$ 

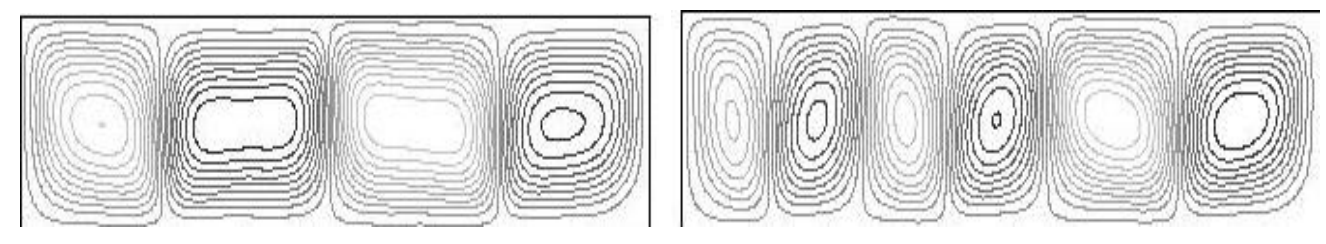

$\phi=5^{0}$
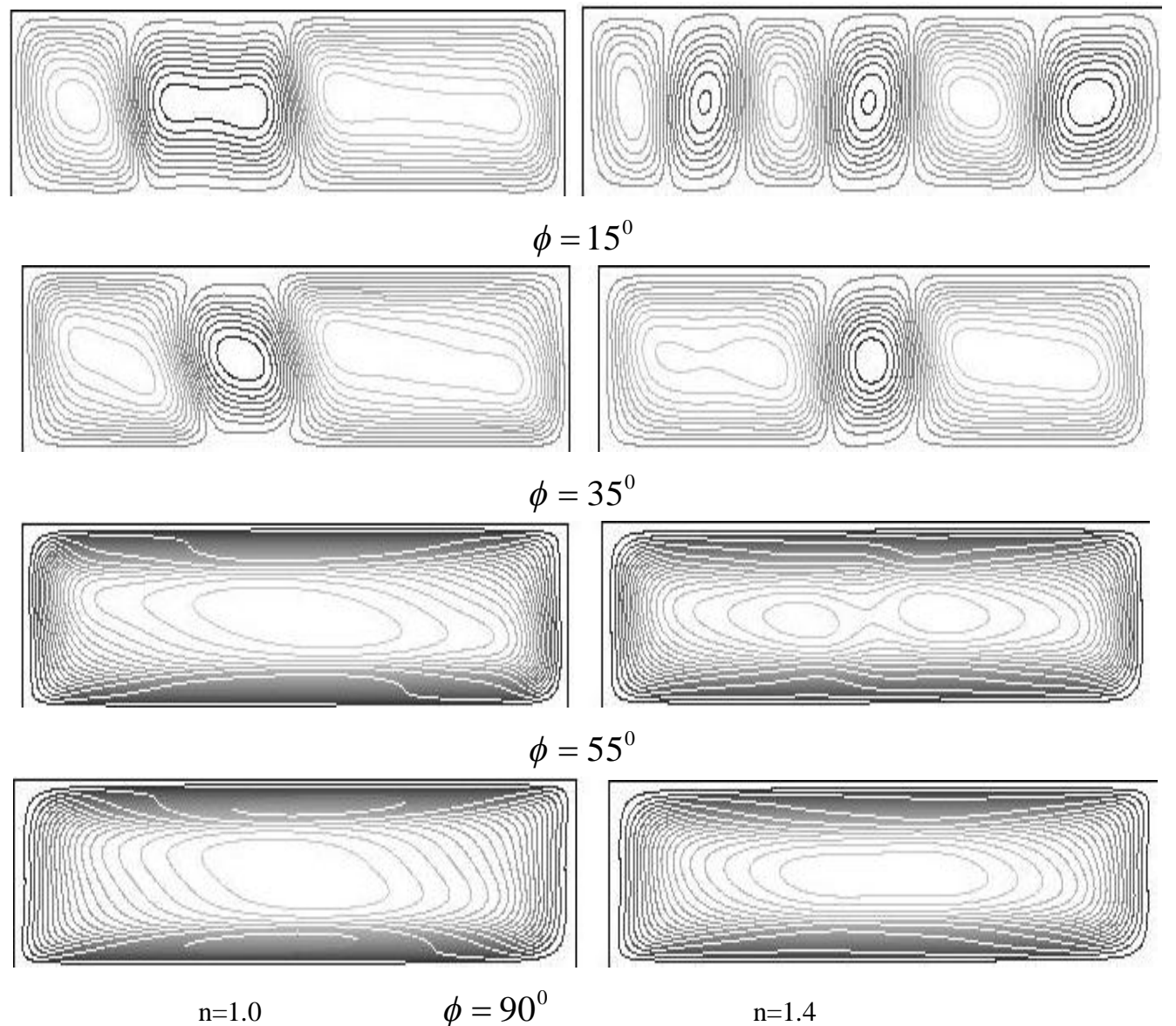

Fig. 8. Contours of stream function, $R a=10^{5}, \operatorname{Pr}=100$ and $\mathrm{AR}=4, n=1$ and $\mathrm{n}=1.4$

\section{REFERENCES}

Corcione, M. (2003). Effects of the thermal boundary conditions at the sidewalls upon natural convection in rectangular enclosures heated from below and cooled from above. Int. J. Thermal Sciences 42, 199-208.

Dale, J., and A. Emery (1972). The free convection of heat from a vertical plate to several nonNewtonian pseudoplastic fluids. ASME J. Heat Transfer 94, 64-72.

Emeri, A., H. Chi, and J. Dale (1971). Free convection through vertical plane layers of non-Newtonian power law fluids. ASME J. Heat Transfer 93, 164171.

Gebhart, B., Y. Jaluria, R.L. Mahajan, and B. Sammakia (1988). Buoyancy Induced Flows and Transport. Hemisphere, Washington, D.C.
Getachew, G., W. Mincowycz, and D. Poulikakos (1996). Natural convection in a porous cavity saturated with a non-Newtonian fluid. $J$. Thermophys. Heat Transfer 10, 640-651.

Inaba, H., C. Daib, and A. Horibe (2003). Natural convection heat transfer of micro-emulsion phasechange-material slurry in rectangular cavities heated from below and cooled from above. Int. J. Heat Mass Transfer 46, 4427-4438.

Khalifa, A.J.N. (2001). Natural convective heat transfer coefficient - a review, II. Surfaces in two- and three-dimensional enclosures. Energy Convers. Manage. 42, 505-517.

Khezzar, L., and D. Siginer (2009). Natural convection in inclined two-dimensional rectangular cavities. Proceedings of the fluids engineering division summer meeting, paper FEDSM2009-78566, 
I. Vinogradov et al. / JAFM, Vol. 4, No. 2, Special Issue, pp. 37-42, 2011.

ASME Fluid Engineering Division Summer, August 2-5, Vail, Colorado, USA.

Kim, G.B., J.M. Hyun, and H.S. Kwak (2003). Transient buoyant convection of a power-law nonNewtonian fluid in an enclosure. Int. J. Heat Mass Transfer 46, 3605-3617.

Lamsaadi, M., M. Naimi, M. Hasnaoui, and M. Mamou (2006). Natural convection in a tilted rectangular slot containing non-Newtonian power-law fluids and subject to a longitudinal thermal gradient. Numer. Heat Transfer A 50, 561-583.

Ohta, M., M. Akiyoshi, and E. Obata (2002). A numerical study on natural convective heat transfer of pseudo-plastic fluids in a square cavity. Numer. Heat Transfer A 41, 357-372.

Ostrach, S. (1972). Natural Convection in Enclosures. in Harnett J.P., Irvine T.F. (Eds), Advances in Heat Transfer 8, Academic Press, London.

Ozoe, H., and S. Churchill (1972). Hydrodynamic stability and natural convection in Ostwald-De Waele and Ellis fluids: the development of a numerical solution. AIChE J. 18, 1196-1207.

Pittman, F.F.T., J.F. Richardson, and C.P. Sherrard (1999) An experimental study of heat transfer by laminar natural convection between an electricallyheated vertical plate and both Newtonian and nonNewtonian fluids, Int. J. Heat Mass Transfer, 42, 657-671.

Soong, C.Y., P.Y. Tzeng, D.C. Chiang, and T.S. Sheu (1996). Numerical study on mode-transition of natural convection in differentially heated inclined enclosures. Int. J. Heat Mass Transfer 39, 28692882.

Tien, C., H. Tsuei, and Z. Sun (1969). Thermal instability of a horizontal layer of non-Newtonian fluid heated from below. Int. J. Heat Mass Transfer, Shorter Commun. 12, 1173-1178. 